\title{
Cooperative Multi-Agent Vehicle-to-Vehicle Wireless Network in a Noisy Environment
}

\author{
Ayman M Mansour, \\ Communication, Electronics and Computer Engineering Department, \\ Tafila Technical University \\ 'Is, Tafila 66110 \\ Jordan
}

Received: July 20, 2020. Revised: February 1, 2021. Accepted: February 15, 2021. Published: February 22, 2021.

\begin{abstract}
With the rapid development of vehicle communication and the goal of self-driving vehicle, research in this area is still ongoing, as car companies aspire for more studies and effective communication methods between vehicles. In this research, we have developed an intelligent, innovative and fully integrated multi agent model, which is used for vehicle-to-vehicle communications. The developed model is supported by an intelligent system based on a Nonlinear External Neural Network (NARX) and signal estimation theory. The system is built using real vehicles sensors, Arduino, GSM and RF technologies. The system is tested by applying different scenarios and observing vehicle behaviors. The results show that the smart system is able to make the appropriate decision based on both the vehicle's current condition and sensor readings. The developed system is able to operate effectively in a noisy environment in an excellent manner.
\end{abstract}

Keywords-Decision System, Multi- Agent System, NARX, Noisy Environment, Vehicle-to-Vehicle Communication.

A

\section{INTRODUCTION} faster than ever, and new technologies will enter successively in the near future, regardless of whether or not the consumer requests these technologies in his new vehicle. In addition to vehicle companies, there are a lot of companies which are specialized in technologies participate in the development of these technologies. It is expected that this kind of industry will be more developed during the next five years than it was developed in the past fifty years [1-14]. Many new technologies are still in the development stage at the present time, and they are related to the driver and passengers' convenience and their essential protection [15-30].

The technology behind vehicle-to-vehicle communication relies on radio transmitters and receivers in vehicles [31-38], which can transmit information to infrastructure and other vehicles hundreds of meters away. The safety factor, of course, is the main driver of this technology. Inter-vehicle communications enable vehicles to transmit their locations, speeds, directions, and other information between vehicles in the same or different area. For example, this communication can allow vehicles to determine whether the driver is pressing the brake pedal too hard, suddenly changing lanes, or turning around an invisible curve in time to prevent an accident.

Vehicles can send road conditions to the infrastructure, which, in turn, will send them directly to other vehicles. Among the information that can be exchanged between vehicles is the time when traffic light is green or red to avoid traffic congestion. The vehicle-to-vehicle communication system operates at wide range of up to 1000 meters in all directions even with obstacles due to the presence of buildings or any other obstacles. This distinguishes this kind of technology with its ability to detect potential accidents before the driver sees the danger that threatens him. Unlike the sensors and autonomous cameras of vehicles, which determines just what is happening in time around the vehicle.

Vehicle-to-vehicle communication system messages must be encrypted for privacy protection purposes; that is, it should not contain any information about the driver, vehicle owner, vehicle model, vehicle number, or driver's license. In addition to these services, the vehicle-to-vehicle communication system guarantees the communication between vehicles enable them to broadcast their locations. It can also transmit speed, direction and other information ten times per second. It enables vehicles to determine if another vehicle will flash hazard light or apply the brakes. There is no consensus on the best connection standard yet, since 2016 Mercedes had adopted network communication technology, which directs vehicle information to other Mercedes vehicles through a secure cloud service.

The way that this technology works is as fellow: Vehicle A moves forward for several kilometers and sends information to Vehicle B about an obstacle on the road, allowing the driver of Vehicle B to choose an alternate route or slow down. Sudden occurrence of an alternate recommended road, lane or speed limit. This information is sent to a receiver on the designated road, then the device, in turn, passes it on to other vehicles. 
One possible platform for communication between the vehicles is through the usage of the GSM network at different frequencies. Also, there are other technologies such as ad hoc short range communications. Short range communications are used to alert drivers of potential problems at a distance of 300 meters. This connection can enhance the functionality of adaptive cruise control systems. Wireless communication technology is another popular technology that allows vehicles to exchange data (Wi-Fi wireless technology) using high-speed networks. The consensus of many stakeholders that the marketing advantage provided by advanced driver assistance systems is very important in communication between vehicles.

A multi-agent system is developed in this paper for vehicle to vehicle communication in a noisy environment. The multisystem system has been a hot topic in recent years [39-43]. It remains a field of research and development due to its great influence and pioneering applications in matters related to security, human safety and facilitating life. The developed system consists of a group of agents who share information and decisions and proactively help each other to achieve the goal of driver comfort and safety. The agents in the developed system will be equipped with intelligent decision maker that arms the agents with the reasoning capability that can assist in making instantaneous decisions that protect vehicles and facilitate traffic. Having a smart communication system makes communication between vehicles faster and better.

Wireless communication channels become an integral part of communication between vehicles. The existence of communication channels requires signal sampling, quantizing, and estimation. This adds new dynamic behavior to the developed multi-agent system.

Obeidat et al. in [44], [45] and [46] developed a new methodology for real-time control-oriented identification and signal estimation using quantitative sensing information. PMDC motors were used to develop the system, where PMDC motors are the most important parts used in electric and hybrid transmission and their auxiliary subsystems. This study resulted in reducing the system sensing costs and communication resource consumption; also, the system reliability was enhanced by simplifying system configuration and packaging.

In [47], Authors develop an identification system that collects data on braking system using DC servo motor. This assists drivers to avoid sudden braking accidents.

In order to preserve the safety of drivers and vehicles, an intelligent communication system must be developed to reduce accidents on the roads [47]. One of Salient features in machine learning approach related to vehicle communication is to develop agents that deal with large variety of threats [48].

In this paper, Vehicle-to-Vehicle communication system is is designed to transfer and share information between vehicles such that, the system delivers warning signals for drivers and other vehicles. The develop system consists of three parts. The first part is the development of multi agent system in noisy environment. The second part is the decision system to predict the alarm percentage of a vehicle. The last part is the implementation of the system.

\section{Developed Vehicle to Vehicle Multi-Agent System}

We have further developed the multi-agent system that we conceptually put forward before [39]. The main objective of the work is to build a multi-agent system with noise immunity that can successively transmit data and decisions between vehicles.

The vehicles in the developed system are divided into several virtual groups called clusters as shown in Figure 1. Each cluster is formed from the head of the group, which is the main vehicle that sends the signal and group members who are the rest of the vehicles that fall within the power coverage range of the main vehicle.

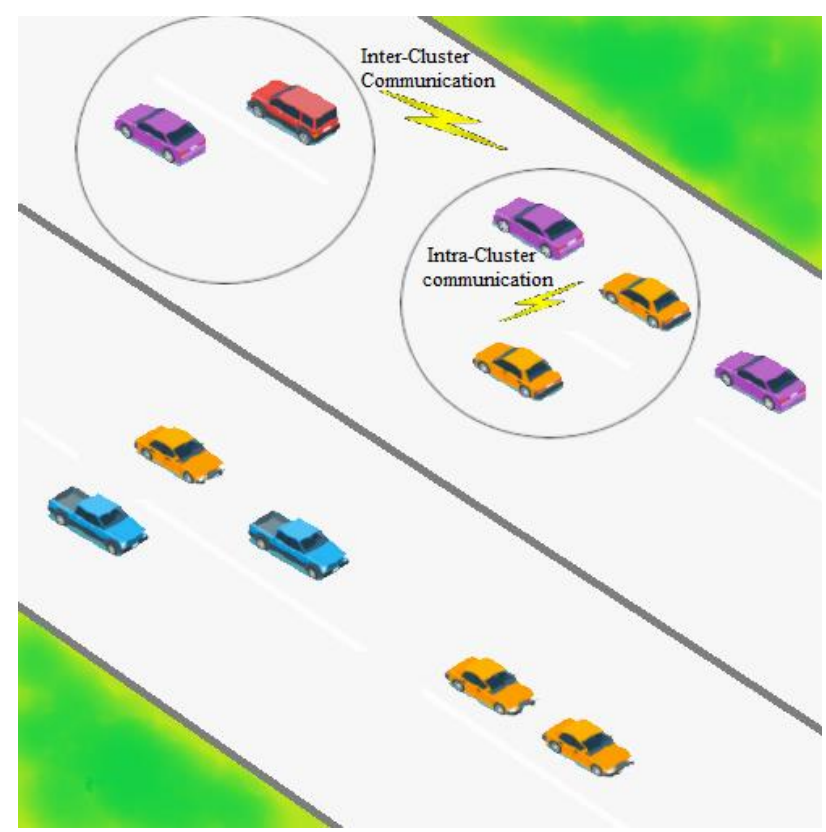

Fig. 1. An illustrative structure of vehicular networks.

The communication between clusters takes place between the first main vehicle from the first cluster and the first main vehicle from the second cluster. Communication within a cluster (intra cluster communication) or between clusters (inter cluster communication) is primarily intended to successfully send data to the destination.

Figure 2 shows the structure of the developed Vehicle Monitoring Agents (VMA). The main components of VMA are decision maker unit, deliberative engine, knowledge bases and communication module. More details of these components are found in our previous work [39]. Interaction between Vehicle Monitoring Agents occurs within a scene. A VMA can communicate with other VMAs in the same or different driving zones through communication module. The developed system is composed from several scenes based on the readings of the sensors. The scenes and sensors readings are stored in knowledge databases. A protocol of a scene is considered to be the specification of the possible dialogues that participating agents have. Possible dialogues are managed by deliberative engine. 


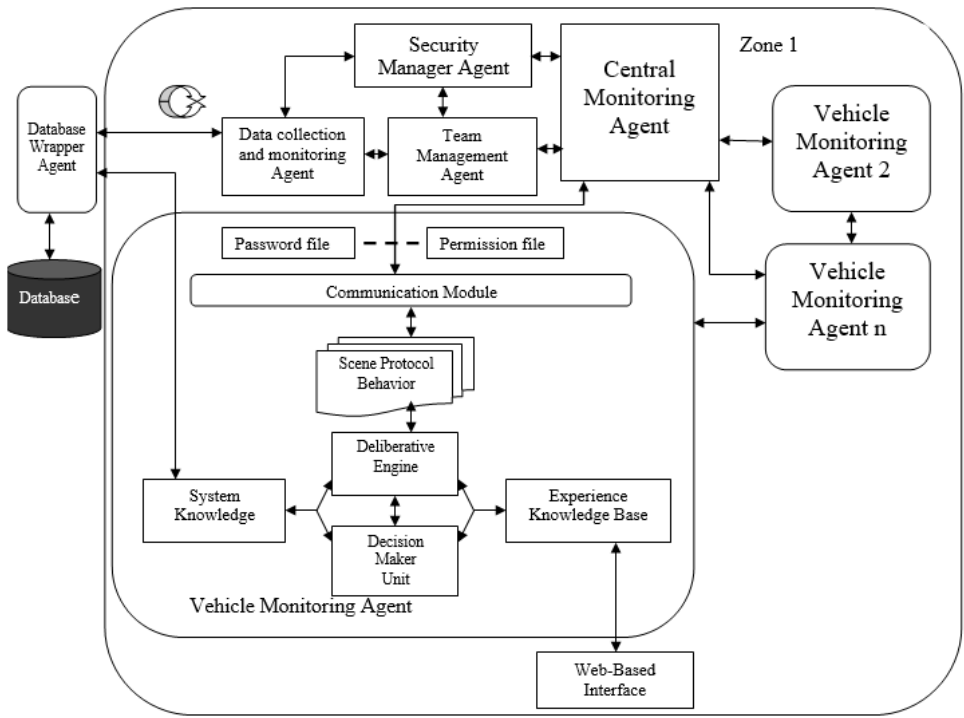

Fig. 2. General architecture of a Vehicle Monitoring Agent in a vehicle to vehicle multi-agent system.

A scene is described as a graph that shows the change in an agent's state from one state to another. The graph contains nodes and arrows. The nodes show the different states of conversation between the agents. The arrows represent the transitions between states. The graph contains one initial state and a set of end states that represent different endings of the expected conversation in a scene. Figure 3 shows a state diagram of a scene where Set $=\{\mathrm{S} 1, \mathrm{~S} 2, \mathrm{~S} 3, \mathrm{~S} 4\}-$ a set of states in a scene:

S1 - initial state;

S2 - waiting for a response to the request;

S3 - checking the data;

S4 - lack of communication;

S5 - data processing and decision making,

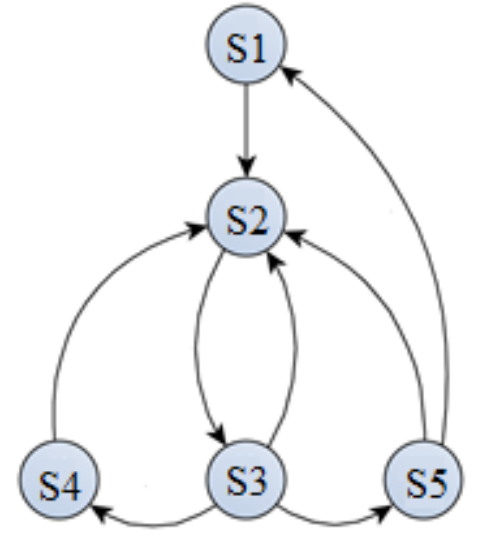

Fig. 3. The state diagram of a scene in multi agent environment.

In the developed multi- agent system, an agent cannot only communicate with a single message, but also have a "conversation." The multi- agent environment provides Vehicle Monitoring Agents with the ability to exchange information and actions in a well-defined structure. The VMAs interact with the
Central Monitoring Agent to get some driving environment observations. The structure of a communication scheme is shown in Figure 4. Agents cooperate with each other to enhance the driving behavior and decrease the number of accidents.

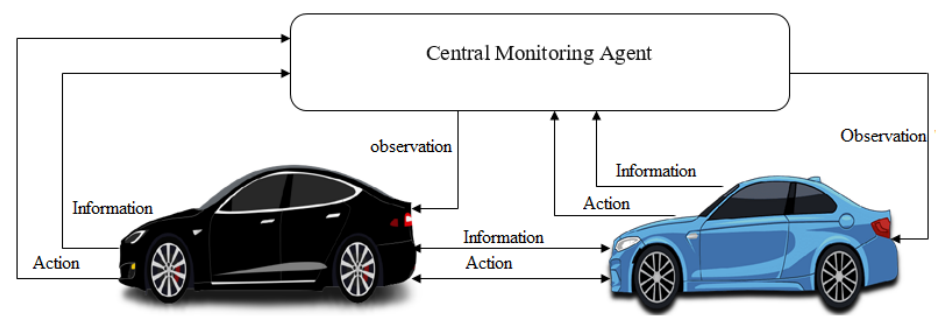

Fig. 4. The structure of multi-agent communication scheme.

Wireless communication are strongly dependent on the distance between the sender agent and receiver agent. This affects the performance when the sensors are wirelessly connected to the main unit. Vehicle Monitoring Agents are able to perceive the surrounding environment, and respond in a timely manner to changes that occur in it. Agents are also able to interact intelligently with other Vehicle Monitoring Agents. One of the main advantages of the developed multi-agent system in use: It defines a clear structure of representing an agent, a group of agents and messages between agents. It is relatively easy to provide all designed agents with different tasks [41-43], [49].

The developed multi-agent platform encourages the use of distributed intelligence to support the vehicle to vehicle communication. The autonomous communication between Vehicle Monitoring Agents has many visible and encouraging results, as consequence of the used decision support of NARX system. The develop decision system that is used by a VMA is shown in Figure 5.

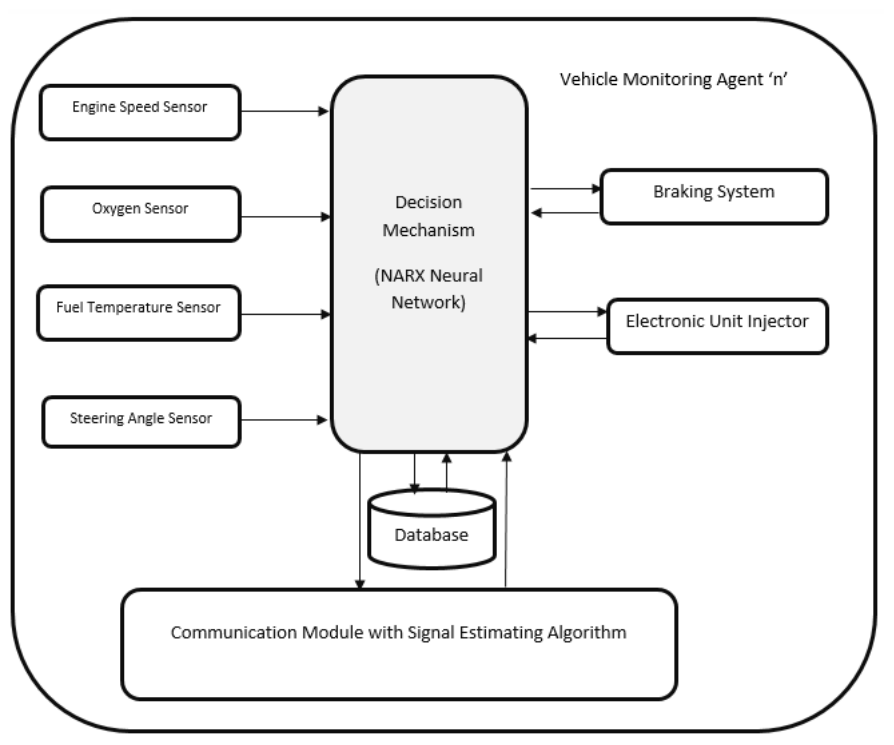

Fig. 5. General architecture of Vehicle Monitoring Agent. 
The monitoring data of a vehicle is gathered using real sensors. The data is collected from engine speed sensor, oxygen sensor, fuel temperature sensor, braking system and steering angle sensor. The data is fed to the NARXs Decision system. As a result, the decision system activates the braking system either by turning it On or Off. The rotation speed of of the engine is affected by the decision system as well. The speed is controlled to be decreased or increased through Electric Unit Injector Unit by injecting more or less fuel.

The NARX decision system makes use of the historical data gathered from driver's behaviors in previous trips. At the same time, the decision is sent to other surrounded vehicles through communication module. The sent decision controls the speed of the surrounded vehicles and activates its braking system if the system is pre-set.

\section{Decision Model Using Nonlinear Autoregressive EXOGENOUS (NARX) NEURAL NETWORK}

Nonlinear Autoregressive Exogenous (NARX) Neural Network is used to develop a decision model that is capable to predict that a vehicle has abnormal behavior. The system uses sensors data. The NARX network is suitable for the nonlinear and auto-regressive nature of the vehicle sensors time series data [50]. NARX has become popular in the last few years for its performance in the prediction of time series. It is shown that NARX networks can provide optimal predictions without computational losses in comparison with the conventional recurrent neural networks (RNNs). The NARX network follows the concept of autoregressive model in time series forecasting [51]. It is a recurrent dynamic network, with feedback connections to several layers of the network [52]. A relevant study can be found in [53].

The NARX network is a feed forward neural network with three layers; input, hidden, and output layers. NARX network is used to solve a time series problem. NARX neural network uses historical data of the variable in order to make decision. The topology of a NARX network is shown in Figure 6. The number of delays and the number of neurons in the hidden layer are adjustable. These numbers are optimized through trial-anderror testing in order to get accurate model responses.

Future values of time series values $y(n)$ are predicted based on its delays values as shown in (1),

$$
\begin{aligned}
& Y(n)=\sum_{j=1}^{m} w_{j} *\left[f\left(\sum_{i=1}^{k} w_{i j} Y(n-i)+w_{0 j}\right)+\right. \\
& \left.f\left(\sum_{i=1}^{k} w_{i j} X(n-i)+w_{0 j}\right)+\right]+w_{0}+\varepsilon
\end{aligned}
$$

Where $\mathrm{k}$ is the number of delays, $\mathrm{m}$ is the number of neurons in a hidden layers with activation function $\mathrm{f}$, and $\mathrm{w}_{\mathrm{ij}}$ is the weight of the connection between the input $i$ and the hidden neuron $j$. $\mathrm{w}_{\mathrm{j}}$ is the weight between the hidden neuron $\mathrm{j}$ and the output layer. $w_{o j}$ is the initial weights (bias) between input layer and $j$ neuron in the hidden layer, and $\mathrm{w}_{\mathrm{o}}$ is the initial weight of the output layer. $\varepsilon$ is the error of the approximation of the series at a given time. The most commonly used activation function $f$ in neural network is Sigmoid function.

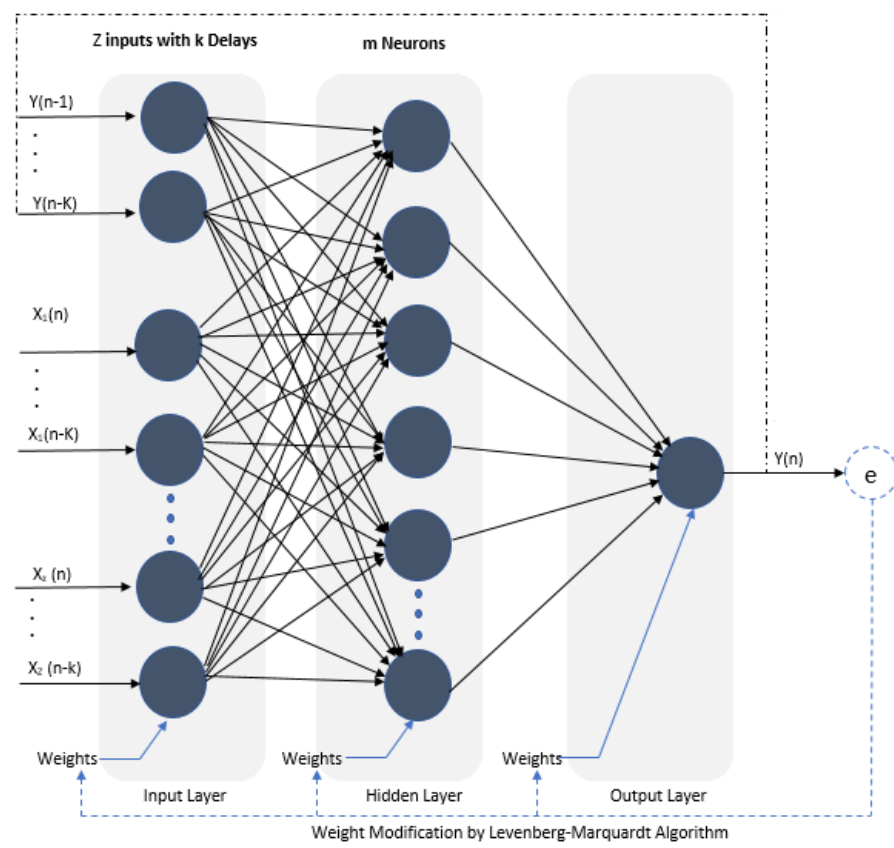

Fig. 6. Nonlinear autoregressive exogenous neural network.

The general prediction equations for computing the next value of time series $Y(n+1)$ uses the past observation $X_{1}(n), .$. $X_{1}(n-k), \ldots, X_{Z}(n), . ., X_{z}(n-k)$ and the past outputs $Y(n), Y(n-1)$, $\ldots, Y(n-k)$ as inputs. During the training stage, the neural network optimize the network weights and neuron bias in order to get the output Y. After training, the developed model is used to predict the vehicle behavior.

The most common learning rule for the NARX network is the Levenberg-Marquardt Algorithm. The LevenbergMarquardt (LM) algorithm is a back propagation algorithm. It has been widely used for training the NARX network because of the fast convergence speed. The LM algorithm uses an approximation of the Hessian matrix without direct calculation, therefore its training speed is increased. The LM equation to update the weights is shown in (2),

$\mathrm{w}_{\mathrm{k}+1}=\mathrm{w}_{\mathrm{k}}-\left[\mathrm{J}^{\mathrm{T}} \mathrm{J}+\delta \mathrm{I}\right]^{-1} \mathrm{~J}^{\mathrm{T}} \mathrm{e}\left(\mathrm{w}_{\mathrm{k}}\right)$

where $\mathrm{J}$ is the Jacobian matrix, $\mathrm{I}$ is the identity matrix, and e is the network errors. The Jacobian matrix is the first derivatives of the error with respect the weights $\mathrm{w}_{\mathrm{k}}$. The Hessian matrix is $\mathrm{J}^{\mathrm{T}} \mathrm{J}$ and the gradient is $\mathrm{J}^{\mathrm{T}} \mathrm{e}$. The effectiveness of the model is measured by using mean squared error (MSE) and $\left(\mathrm{R}^{2}\right)$ as shown in (3) and (4) respectively.

MSE $=\frac{1}{n} \sum_{i}(y i-\hat{y})^{2}$
$\mathrm{R}^{2}=1-\frac{\sum_{\mathrm{i}}(\mathrm{yi}-\widehat{\mathrm{y}})^{2}}{\sum_{\mathrm{i}}(\mathrm{yi}-\overline{\mathrm{y}})^{2}}$

Where yi is the actual value of the sample $i$ and $n$ is the number of samples, $\hat{y}$ is the forecasted value and $\bar{y}$ is the average value. When the resulted amount of these equations is small, the performance of prediction is better. The developed algorithm is summarized in Figure 7. 


Vehicle Behavior Prediction Algorithm
1: Read sensors data
2: Prepare data for training and simulation
3: Setup data division for training, testing, and validation
4: Create NARX neural network model
5: Choose number of delays and number of neurons in hidden
layer
6: Choose a performance function
7: Train, test, and validate the model
8: Run performance checking
9: if passes then
10: Select model specification
12: else
13 Repeat step 7
14: end if
15: Return specification and model ready for decision

Fig. 7. Vehicle behavior prediction algorithm.

\section{MULTI-AGENT SYSTEM IN A NOISY ENVIRONMENT}

When a signal is transmitted to the surrounded vehicles, it is sampled, quantized, and then transmitted through communication module of a vehicle Monitoring Agent to other Vehicles Monitoring Agent and Central Monitoring Agent as shown in Figure 8 and Figure 9.

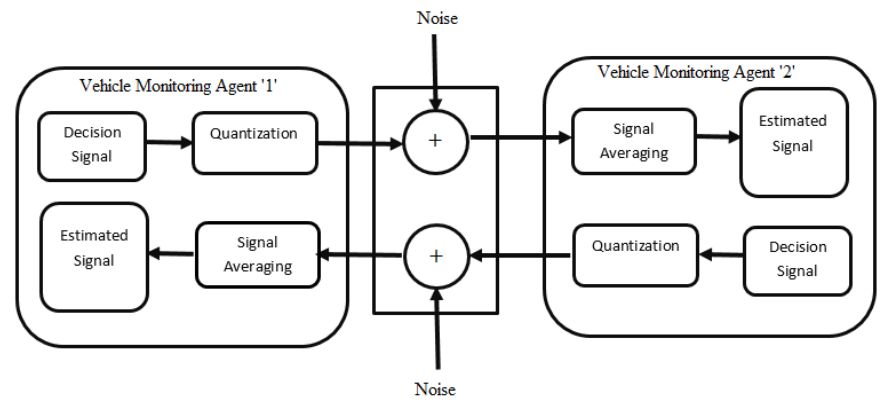

Fig. 8. Closed loop VMA to VMA communication system.

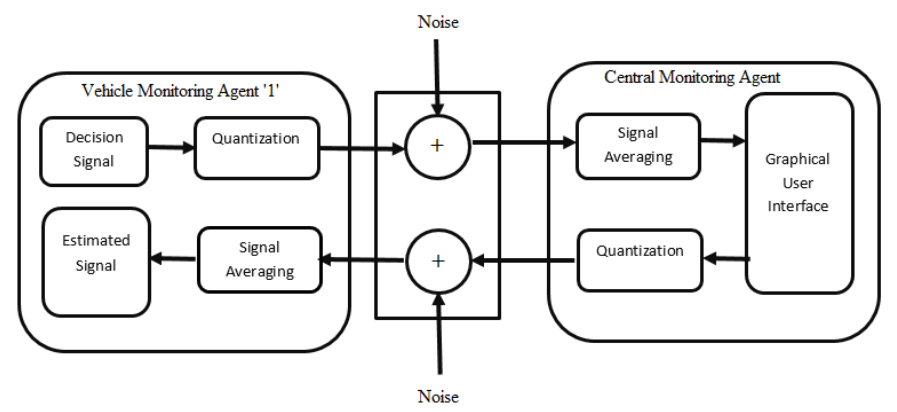

Fig. 9. Closed loop VMA to Central Monitoring Agent communication system.

At the receiving Vehicle Monitoring Agent, the signal is recovered and estimated. Communication channels encounter time delays and noise. The used method for estimating the transmitted signals is averaging method, which is commonly used in signal recovery schemes. It is used to reduce signal estimation errors and eliminate noises on the transmitted signals.

The used signal estimation methodology is introduced in [45], and [46]. This estimation algorithm has not been used previously in a multi-agent system. It is shown in [45] that the algorithms which extract information on the original signals act as averaging filters. Low-precision quantization, such as binary-valued quantization, will not transmit sufficient information on the signals for feedback control. However, more information is recovered by employing the smoothing effects of random noises.

The output transmitted signal is denoted by $\mathrm{L}_{\mathrm{k}}$. The true transmitted signal $\mathrm{v}_{k}$ is bounded $\mathrm{L}_{\min } \leq \mathrm{L}_{k} \leq \mathrm{L}_{\max } . \mathrm{L}_{k}$ is either affected with a measurement noise or with a random noise $n_{k}$ added to enhance signal estimation.

The signal with added noise $\mathrm{L}_{\mathrm{k}}+\mathrm{N}$ is quantized to get a a quantization function $\mathrm{S}\left(\mathrm{L}_{\mathrm{k}}+\mathrm{N}\right)$. The signal $\mathrm{L}_{\mathrm{k}}+\mathrm{N}_{\mathrm{k}}$ is quantized by $\mathrm{Q}$ quantization thresholds $\left\{\mathrm{h}_{1} \ldots \mathrm{h}_{\mathrm{Q}}\right\}$, which divides the range $\left[\mathrm{L}_{\min }, \mathrm{L}_{\max }\right]$ into $\mathrm{L}_{\min }<\mathrm{h}_{1}<\cdots<\mathrm{h}_{\mathrm{Q}}<\mathrm{L}_{\max }$. The output of the quantizer takes $\mathrm{Q}+1$ possible values which are represented in the set $=\{1,2, \ldots, Q+1\}$. The resulted signal is represented in (5),

$\mathrm{s}_{\mathrm{k}}=\sum_{\mathrm{i}}^{\mathrm{m}+1} \mathrm{i} * \mathrm{I}_{\mathrm{h}_{\mathrm{i}-1}<\mathrm{L}_{\mathrm{k}}+\mathrm{N}_{\mathrm{k}} \leq \mathrm{h}_{\mathrm{i}}}$

with $\mathrm{h}_{0}=0$ and $\mathrm{I}$ being the identity function. If a binary quantization is used with $\mathrm{h}$ threshold, $\mathrm{s}_{\mathrm{k}}$ is represented as in (6),

$s_{k}=\left\{\begin{array}{l}1, L_{k}+N_{k} \leq h \\ 0, L_{k}+N_{k}>h\end{array}\right.$

The data point $s_{k}$ sent at time $t_{k}$ is arrived with a delay and a random noise to the the other VMA. The data sequence is not altered due to time-varying delays as a result of FIFO (first-infirst-out) buffers. The binary valued quantization is used to estimate the transmitted signals between vehicles with correct order. (7) defines the exponentially weighted empirical measures if $0<\alpha<1$,

$\lambda_{k}^{\Delta}=(1-\alpha) \sum_{l=-\infty}^{k} \alpha^{k-1} s_{i}$

where the weight is normalized as in (8),

when $\mathrm{s}_{\mathrm{l}}=1,(1-\alpha) \sum_{\mathrm{l}=0}^{\infty} \alpha^{1}=1$

Algorithm can also be written recursively as shown in (9),

$\lambda_{k}^{\Delta}=\lambda_{k-1}^{\Delta}+(1-\alpha)\left(s_{k}-\lambda_{k-1}^{\Delta}\right)$

$=\lambda_{\mathrm{k}-1}^{\Delta}+\beta\left(\mathrm{s}_{\mathrm{k}}-\lambda_{\mathrm{k}-1}^{\Delta}\right)$ 
The signal estimating algorithm uses constant step size $\beta=1-\alpha$. The smaller the $\alpha$ value, the faster the decaying rate. For some small $\delta$ satisfying $0<\delta<1, \lambda_{k}$ is defined in (10)

$\lambda_{\mathrm{k}}=\left\{\begin{array}{cc}\lambda_{\mathrm{k}}^{\Delta}, & \delta<\lambda_{\mathrm{k}}^{\Delta}<1-\delta, \\ \delta, & \lambda_{\mathrm{k}}^{\Delta}<\delta, \\ 1-\delta, & \lambda_{\mathrm{k}}^{\Delta}>1-\delta,\end{array}\right\}$

The estimation of $\mathrm{L}_{k}$ is shown in (11)

$\hat{\mathrm{L}}_{\mathrm{k}}=\mathrm{h}-\mathrm{G}^{-1}\left(\lambda_{\mathrm{k}}\right)$

The used signal-averaging filter is in (12)

$$
\mathrm{F}=\frac{(1-\alpha) z}{z-\alpha}
$$

\section{IMPLEMENTATION OF THE SYSTEM}

A prototype design for vehicle- vehicle communication system is successfully developed. Arduino is used as a base of the multi agent network because of its simplicity and cost. Arduino is combined with different wireless technologies in order to build a network. For inter clusters communication between GSM is used. While Radio Frequency (RF) module is used in intra cluster communication. Each sensor will transmit its data value to a main unit where the data get processed and usedto make a decision in order to be sent to other vehicles.

With the developed system, neighbors' vehicles can get the up-to-date alarm level of surrounding vehicles by receiving an SMS. SMS messages offer an interesting solution. Messages are delivered within seconds. This allows the vehicle to obtain details of abnormal driving alarms before unforeseen situations.

The Vehicle Assistant Agent shown in Figure 10 consists of vehicle sensors connected to the sensor unit which interact with data collection unit, the microcontroller unit, the GSM module, and the RF module unit. The sensors are connected to a data gathering unit which is connected to a microcontroller. The collected data from sensors is used by the microcontroller to make decisions about driving behavior and verify that it is within safe levels.

In the event that the driving behavior is abnormal, the microcontroller unit immediately activates the alarm by operating the buzzer alarm unit and the LED unit begins flashing. At the same time, an alert message will be sent by the microcontroller unit to other vehicles. The data collected from the sensors will be displayed in front of the vehicle's driver on the LCD unit.
Multiple messages are also be sent to the Central Transportation Agency, Civil defense unit or Police station with GPS location of vehicle.

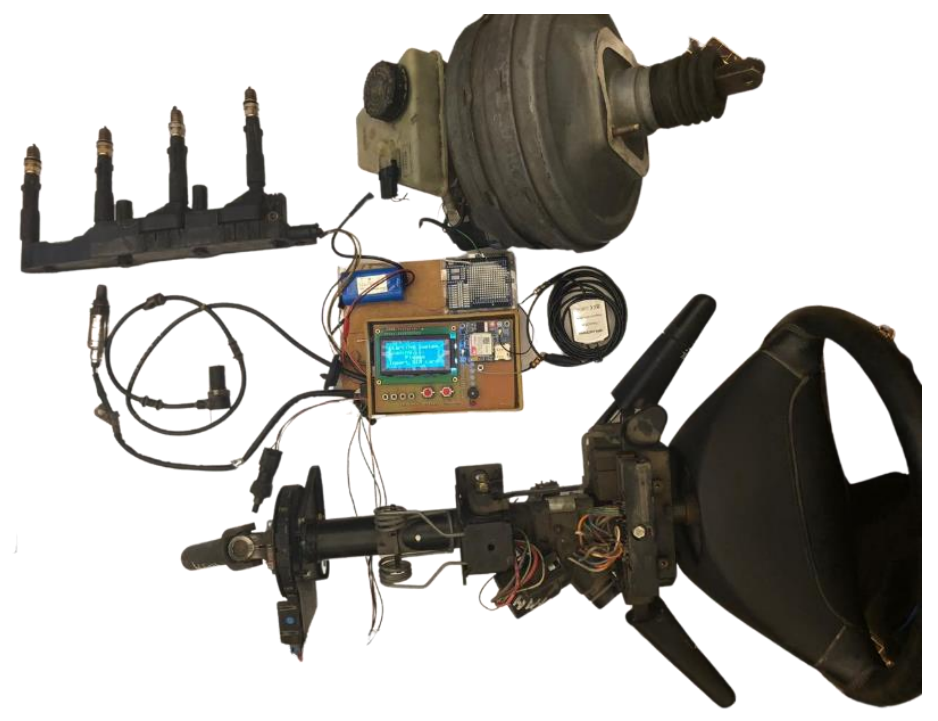

Fig. 10. Vehicle Assistant Agent.

A central processor is provided to the car to control the engine's working mechanism. This is done through the availability of a good number of sensors. For example, the fuel delivery to the engine is controlled, the emissions are monitored, and the anti-slip brakes are activated when needed.

The oxygen sensor (Figure 11) is located in the exhaust pipe. The oxygen sensor monitors the content of gases emitted from the exhaust by measuring the amount of unburden oxygen in the exhaust pipe. This information is used to find out if the engine is running with rich or lean fuel content. The Electric Unit Injector Unit uses this information to determine fuel metering strategy and emission controls.

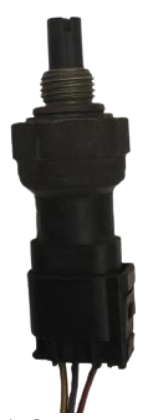

Fig. 11 Oxygen sensor.

The engine speed sensor (Figure 12) measures the rotational speed of the crankshaft itself in RPMs. In order for this sensor to work, there must be a serrated disk and a magnetic coil. As the crank rotates, an electric current is created to generate a magnetic field around the coil. These movements disrupts the magnetic fields and these disruptions are counted into RPM. 


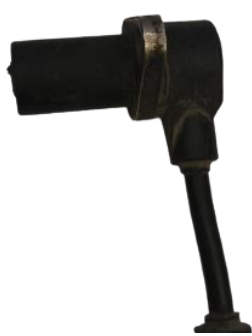

Fig. 12. Engine speed sensor.

The fuel temperature sensor (Figure 13) sends the fuel Temperature to the vehicle Electronic Control Unit (ECU) to specify the amount of fuel to be delivered. Warmer fuels will be less dense and will ignite more quickly than colder fuel which is more dense. If the fuel is warm, the injectors will save more fuel to reach a certain level of mass. A non-functioning fuel temperature sensor leads to a decrease in fuel economy.

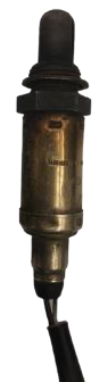

Fig. 13. Fuel temperature sensor.

The steering angle sensor (Figure 14) is based on Giant Magneto-Resistance technology. The unique feature of the steering angle sensor is to provide an absolute steering angle value. The steering angle sensor is installed on the steering shaft. The hub gear wheel transfers the rotational motion of the shaft to two measuring gear wheels. On each measuring gear wheel, a magnet is installed. The direction of its magnetic field changes according to the rotational motion. Below each magnet is a GMR sensor element to detect the angle position of the magnet above.

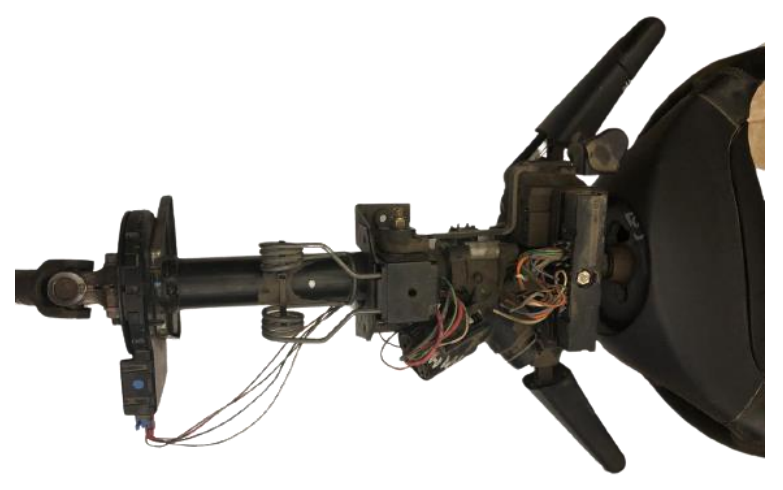

Fig. 14. Steering angle sensor on steering shaft.

The sensed values are converted into digital information directly to be sent to the microprocessor. This measuring principle allows measuring the angle range without using a rotation counter.

Based on the signals received from the main brake servo cylinder (Figure 15) and the pressure sensor on it, Electronic Control Unit (ECU) calculates the speed and amount of brake pedal force to determine the driver's intention to perform emergency braking.

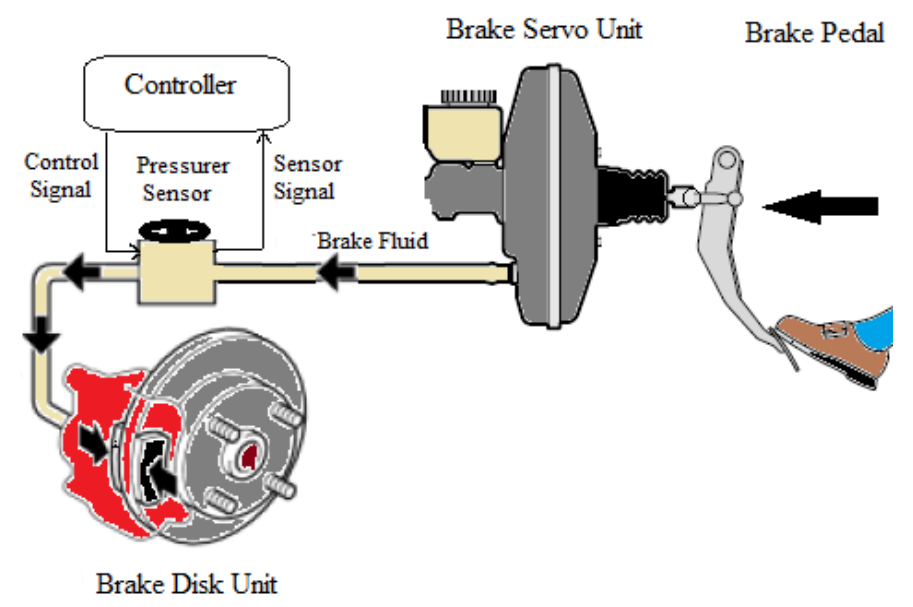

Fig. 15. Layout of an electro hydraulic braking system.

The work of the cylinder converts the force applied from the brake pedal into pressure in the brake fluid, and pushes the fluid from it into the brake tubes and into the wheels' cylinders. The cylinder is mostly made of aluminum alloy (Figure 16), and the cylinder is fixed either to the plate separating the engine compartment and the passenger compartment of the vehicle by means of fixed bolts.

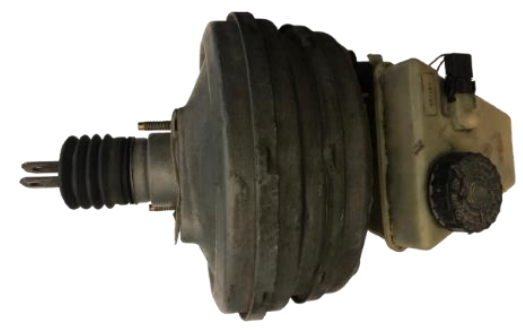

Fig. 16. Brake servo unit.

Spark plug in Ignition spark plug with ignition control unit (Figure 17) has two electrodes which are immersed inside the combustion chamber of gasoline engine (internal combustion engine). To activate the spark plug, it should get the signal either from the distributor or through the ECU. Distributor rotates and determine when butterfly touches and when to disconnect to give the high voltage to the right spark in any cylinder. Based on the firing order ECU get signals from different sensors inside the combustion chamber or on the crank shaft or camshaft that gives a signal to the ignition coil to send high or low voltage to the spark. Spark plug gets its high voltage from the ignition coil. Before getting the high voltage, the fuel air mixture will be working as an insulator in the front of the gap of the spark plug. As the voltage increased the gas get ionized and starts conducting current which will heat up the gas causing an initiation of the ignition process. The flame will 
propagate as fast as possible to ignite the whole mixture in the combustion chamber. As the engine speed increased the new charge will enter to the combustion chamber faster and faster, and thus there might be less time for the flame to cover the whole combustion chamber region

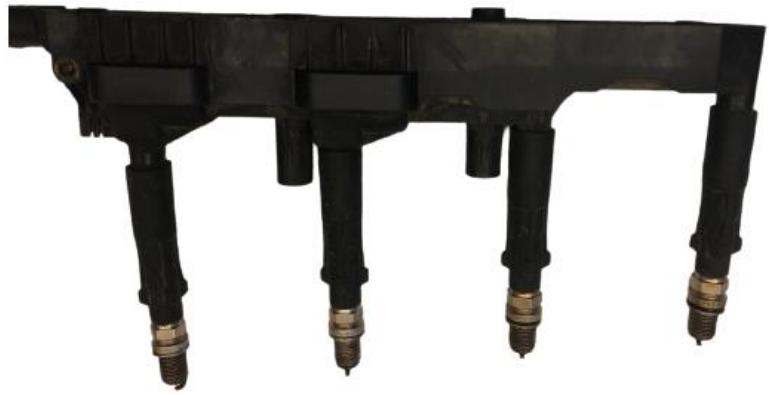

Fig. 17. Ignition spark plug with ignition control unit.

The Receiving alarm unit (Figure 18) receives the transmitted data, supported by the initial decision taken by its VMA. Accordingly, the microcontroller unit starts communicating with the other units attached to it, such as the buzzer alarm unit, the LEDs unit and the LCD screen unit to show the result of the initial decision taken. If the driving risk value is high, the buzzer will be activated, the LED will start to flash and the LCD screen will display the information of the vehicle causing this warning to take caution.

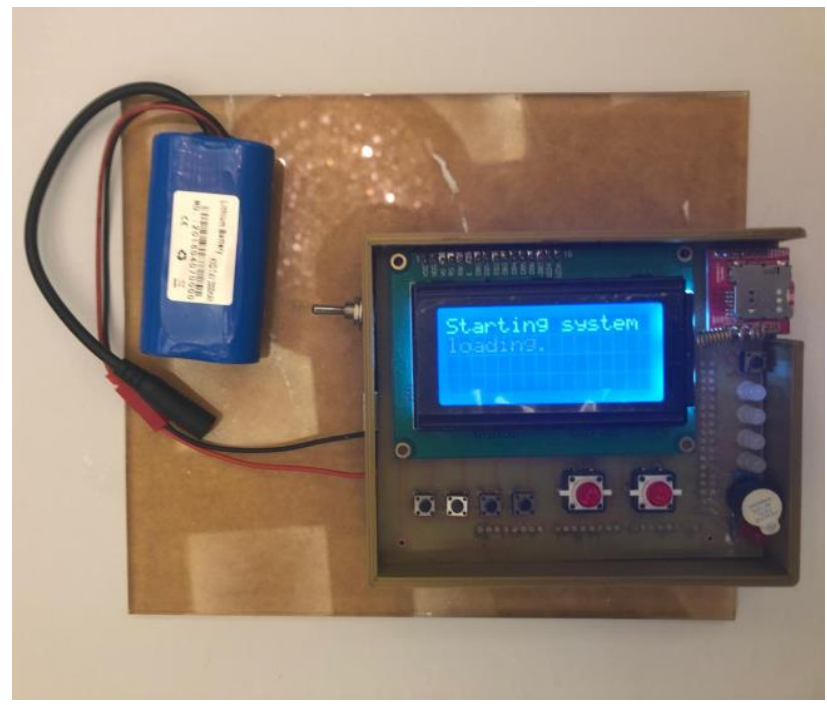

Fig. 18. Receiving alarm unit.

The decision depends on the output of the NARX. In all moments, the Central Transportation Agent can access the network through the graphical user interface as shown in Figure 19. One of the most important components of this agent is the logging and security unit, which allows only authorized persons to access the system. In addition there are other parts which are similar to the VMA, such as the data processing unit and the rule based engine which is decision-making unit. The system can be accessed either via a web browser or an application on the mobile device.
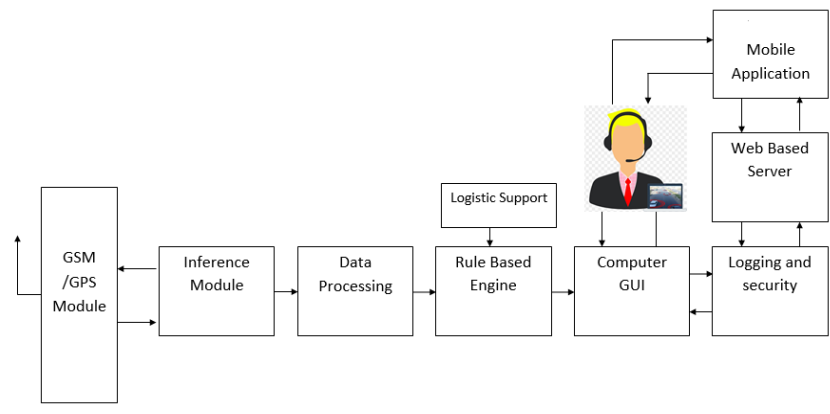

Fig. 19. Central Transportation Agent architecture.

The sensors reading is also accessed through OBD port. It can be wired or wireless through Bluetooth scanner as shown in Figure 20. OBD system is a computer-based system developed by automobile manufacturers to monitor the performance of various components on a vehicle's engine. The main components of the OBD system are: ECU, connectors that send data to the electronic control unit, sensors, malfunction indicator lights and OBD port to get the sensors readings.

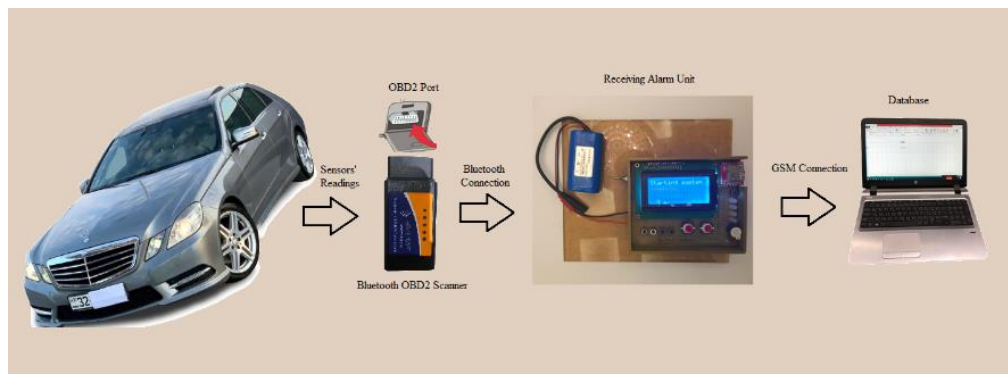

Fig. 20. Data link connector using OBD.

A prototype design for a wireless receiving unit to be used by database has been successfully developed and implemented. Database represents central vehicles database that is responsible for storing vehicles data. Figure 21 shows the wireless receiving unit prototype.
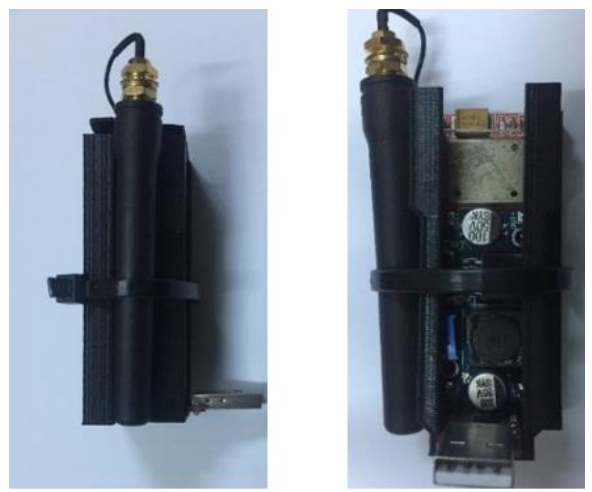

Fig. 21. Wireless receiving unit.

Figure 22 shows the Wireless Receiving Unit prototype connected to laptop (i.e. central database). 


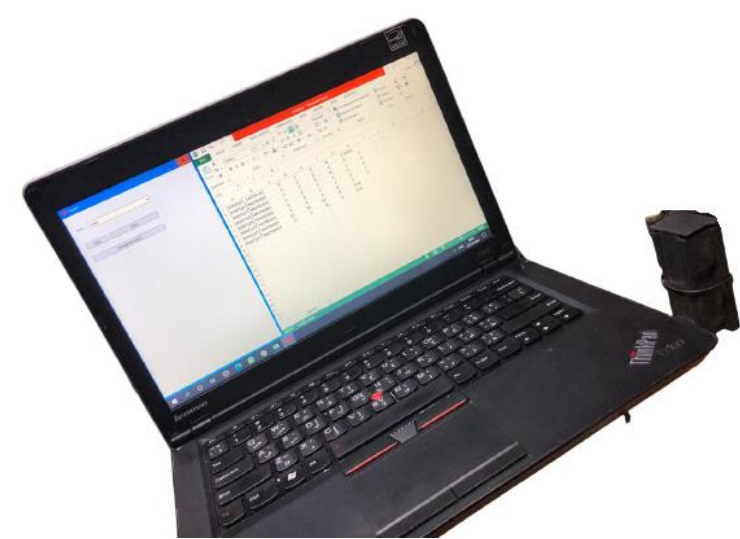

Fig. 22. Central database unit with wireless receiving unit.

A mobile application (Figure 23) is developed to locate and alarm a Vehicle with abnormal driving behavior. It has the ability to send messages to warn the vehicle.

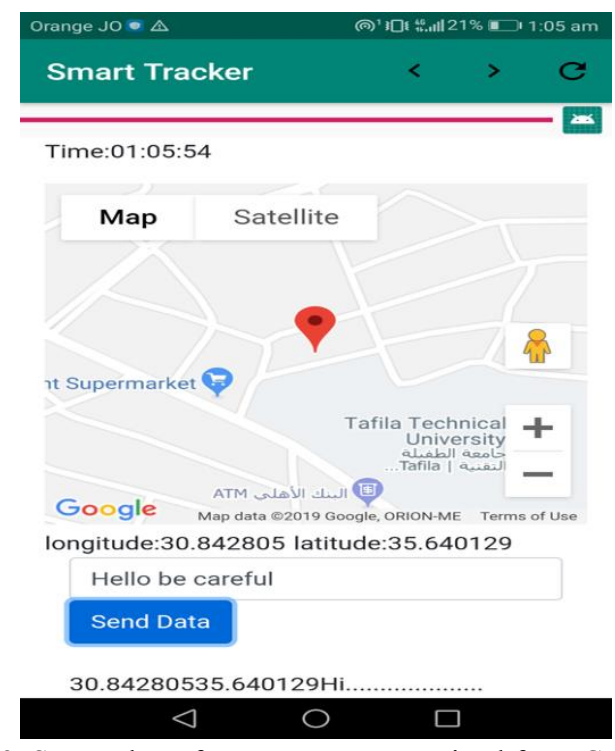

Fig. 23. Screenshot of a text message received from Central Monitoring Agent to a vehicle driver.

\section{EXPERIMENTS AND RESULTS}

To firmly examine the proposed agent system and demonstrate its effective capability for communication, we conducted some evaluation experiments. In an experiment, the first and second Vehicle Monitoring Agents initially registers with a Central Monitoring Agent. Then the two Vehicle Monitoring Agents start communicating with each other to exchange decisions between vehicles such as alarm level. The multi-agent system works successfully as designed.

We examined agreement between the transmitted signal of a Vehicle Monitoring Agent and the received signal of another Vehicle Monitoring Agent. The confusion matrix for each class (normal or abnormal alarm level). The confusion matrix has the form shown in Table 1.
Table 1. General form of confusion matrix

\begin{tabular}{|c|c|c|c|}
\hline & \multicolumn{3}{|c|}{ Actual Transmitted Class } \\
\hline \multirow{3}{*}{$\begin{array}{l}\text { Predicte } \\
\text { d } \\
\text { Received } \\
\text { Class }\end{array}$} & & Class $=$ Normal & Class $=$ Abnormal \\
\hline & Class $=$ Normal & $\begin{array}{c}\text { True Positive } \\
\left(\mathrm{T}_{\mathrm{P}}\right)\end{array}$ & $\begin{array}{l}\text { False Positive } \\
\qquad\left(\mathrm{F}_{\mathrm{P}}\right)\end{array}$ \\
\hline & Class $=$ Abnormal & $\begin{array}{c}\text { False } \\
\text { Negative }\left(F_{N}\right)\end{array}$ & $\begin{array}{c}\text { True } \\
\text { Negative }\left(T_{N}\right)\end{array}$ \\
\hline
\end{tabular}

The used performance measurements are recall, precision, and accuracy. Recall $(\mathrm{R})$ is the ratio of successfully retrieved data among the relevant. Precision $(\mathrm{P})$ is the ratio of the relevant data among the retrieved data. Accuracy, which indicates the fraction of correctly classified samples among all the samples. The formulas are given in (13), (14) and (15) as follow,

$$
\begin{aligned}
& \operatorname{Recall}(\mathrm{R})=\frac{\mathrm{T}_{\mathbf{P}}}{\mathrm{T}_{\mathrm{P}}+\mathrm{F}_{\mathrm{N}}} \text { if } \mathrm{TP}+\mathrm{FN}>0 . \\
& \operatorname{Precision}(\mathrm{P})=\frac{\mathrm{T}_{\mathrm{P}}}{\mathrm{T}_{\mathrm{P}}+\mathrm{F}_{\mathrm{P}}} \quad \text { if } \mathrm{TP}+\mathrm{FP}>0, \\
& \text { Accuracy }=\frac{\mathrm{T}_{\mathrm{P}}+\mathrm{T}_{\mathrm{N}}}{\mathrm{T}_{\mathrm{P}}+\mathrm{T}_{\mathrm{N}}+\mathrm{F}_{\mathrm{P}}+\mathrm{F}_{\mathrm{N}}}
\end{aligned}
$$

The Kappa coefficient is an estimate of the agreement between two raters. Kappa scores range between 1 (complete agreement) and 0. [54] suggested that there is excellent agreement for values of Kappa greater than 0.75 , poor agreement for values less than 0.4 , and fair to good agreement for values between 0.40 and 0.75 .

This experiment uses 24 hours driving trips. Each three seconds an alarm level class is transmitted between two Vehicle Monitoring Agents. The total number of transmitted classes 480 values. Its values are either normal and abnormal. The resulted

\begin{tabular}{|c|c|c|c|c|c|}
\hline & \multicolumn{5}{|c|}{ Actual Transmitted Class } \\
\hline \multirow{5}{*}{ 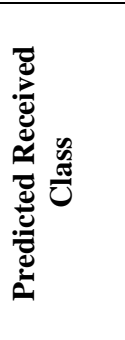 } & & $\begin{array}{c}\text { Class } \\
\text { Normal }\end{array}$ & $\begin{array}{c}\text { Class } \\
\text { Abnormal }\end{array}$ & $\begin{array}{c}\text { Predicted } \\
\text { Overall }\end{array}$ & Precision \\
\hline & $\begin{array}{c}\text { Class } \\
\text { Normal }\end{array}$ & 314 & 5 & 319 & $98.43 \%$ \\
\hline & $\begin{array}{c}\text { Class } \\
\text { Abnormal }\end{array}$ & 6 & 155 & 161 & $96.27 \%$ \\
\hline & $\begin{array}{c}\text { Actual } \\
\text { Overall }\end{array}$ & 320 & 120 & 480 & \\
\hline & Recall & $98.12 \%$ & $96.87 \%$ & & \\
\hline $\begin{array}{c}\text { Overall } \\
\text { accuracy }\end{array}$ & \multicolumn{5}{|c|}{$97.71 \%$} \\
\hline Kappa & \multicolumn{5}{|c|}{0.949} \\
\hline
\end{tabular}
confusion matrix is shown in Table 2.

Table 2. Confusion matrix of the 24 hours driving experiment

In neural networks, choosing type of input variables is as important as choosing appropriate type of neural network and the relevant learning algorithm, It is because if the input variables are not chosen appropriately, neural network may be stopped at the same stage of learning [50]. The NARX model requires less past information than other neural network models to achieve an accurate prediction [50] and [51]. The goal of this experiment was to measure how well the developed system performed in decision-making. 
To assess the effectiveness of the developed decision-making unit, NARX has been trained using 88 driving trips with 1440 records ( 24 hours) for five sensors data engine speed; oxygen sensor, fuel temperature, steering angle, and brake pedal force. Figure 24 to Figure 28 show one hour of a collected data for the five sensors in a trip.

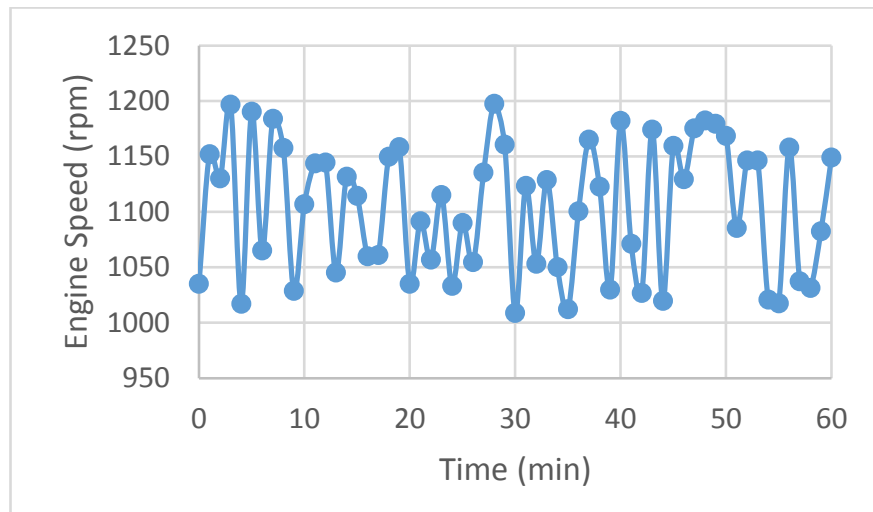

Fig. 24. Engine speed (rpm).

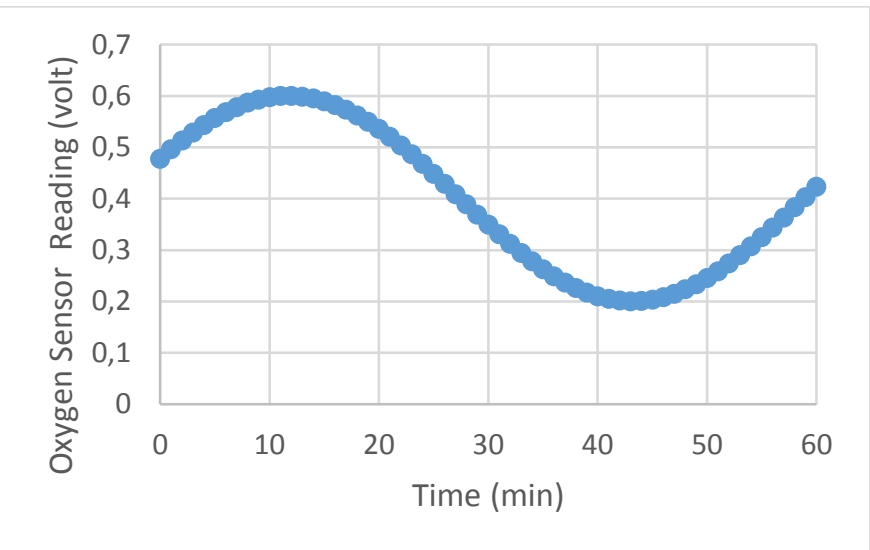

Fig. 25. Oxygen sensor reading (volt).

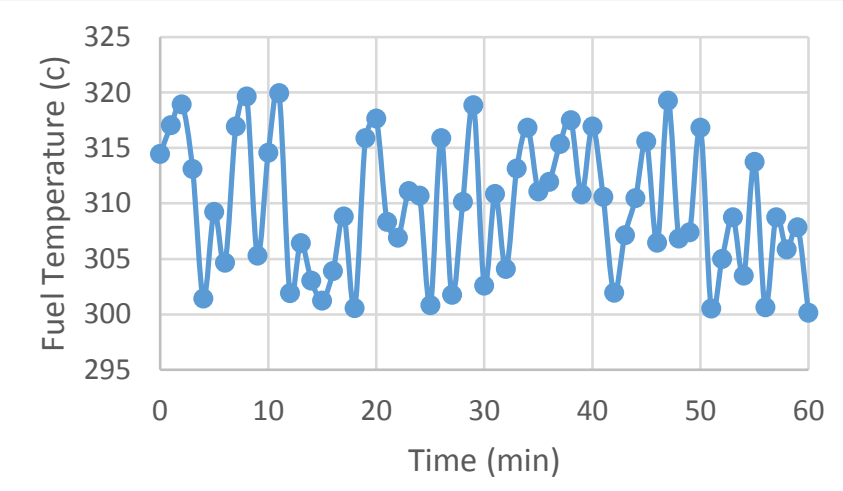

Fig. 26. Fuel temperature (Co).

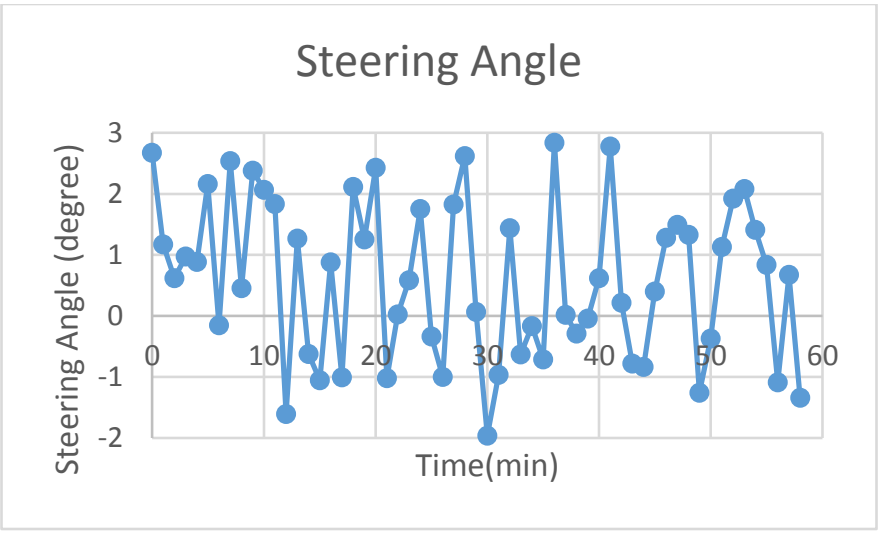

Fig. 27. Steering angle (degree).

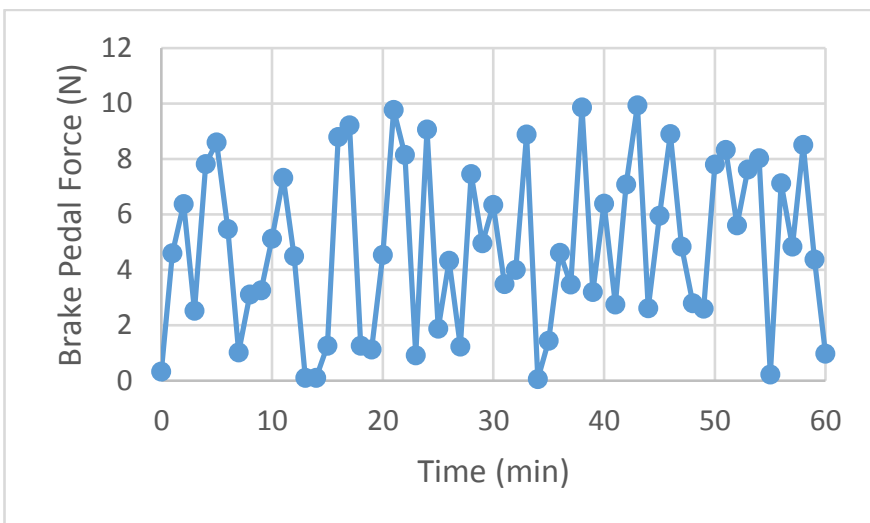

Fig. 28. Brake pedal force (N).

The alarm percentage (\%) of a vehicle is noticed and recorded based on sensor data by two domain experts. If the alarm percentage (\%) is greater than $75 \%$, it will be considered as abnormal. Otherwise, it will be considered as normal. The alarm percentage (\%) of a 60 minutes trip is shown in Figure 29.

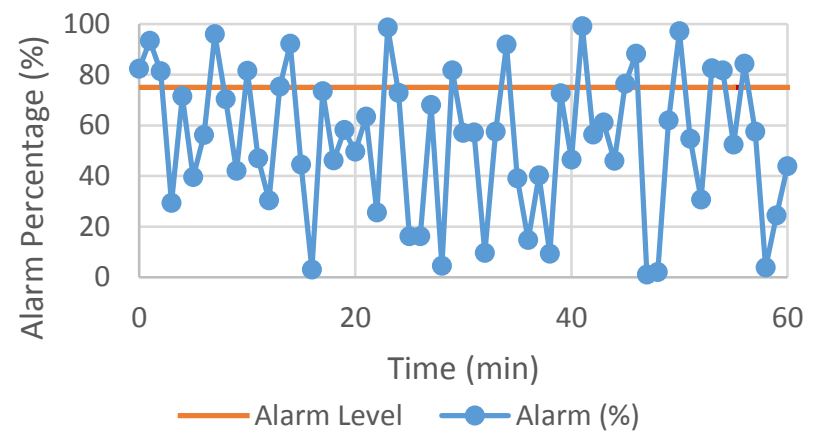

Fig. 29. Alarm percentage (\%).

The collected data is divided into three parts: $70 \%$ for training, $15 \%$ for testing, and $15 \%$ for validation. During the training step the true output, or measured value, is used as the regressive input in the network. Once the network is trained and used for prediction purposes, the calculated output was 
feedback to the network to obtain the estimation for the next prediction step. Figure 30 shows real and a predicted alarm percentage. It is clearly noticed that the predicted alarm percentage is very close to the real alarm percentage signal. This shows that NARX is able to predict the alarm percentage using the five inputs.

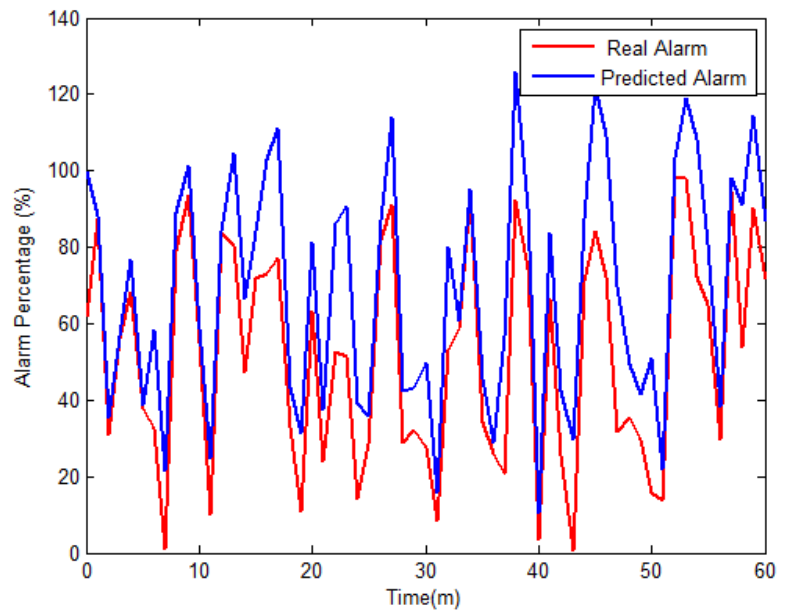

Fig. 30. Real and predicted alarm percentage (\%) by NARX.

The initial weights in the network are assigned randomly, and they are adjusted at each iteration (i.e., epoch) to reduce the error. The procedure continued until the network output met the stopping criteria. The developed NARX model consists of one input layer, one hidden layer, and one output layer. The NARXs are based on LM back-propagation training making decision. MATLAB $B$ software is used to build the models. The NARX structure with 30 hidden neurons was found to be the most effective. It must be noted that increasing the number of neurons in the hidden layer makes a system more complex. Decreasing the number of neurons in the hidden layer will lower the computing power. Decision results of NARX with $\mathrm{n}=30$ neurons in hidden layer and different numbers of delay are shown in Table 3.

Table 3. Number of delays and epoch and R

\begin{tabular}{|c|c|c|}
\hline Delay & Epoch & $\mathrm{R}$ \\
\hline 1 & 22 & 0.32 \\
\hline 3 & 15 & 0.93 \\
\hline 5 & 12 & 1 \\
\hline 8 & 43 & 0.8 \\
\hline 10 & 91 & 0.63 \\
\hline 12 & 31 & 0.78 \\
\hline 15 & 75 & 0.48 \\
\hline
\end{tabular}

NARX performs best when delay is set 5 . This means that 5 earlier records are meaningful to future detection. When the delay is larger than 5 , it will cause over fit issue which makes the trained network less adaptable. Results of NARX with delay $=5$ and different numbers of neuron in hidden layer are shown in Table 4.
Table 4. Number of neuron in hidden layer and Epoch and R

\begin{tabular}{|c|c|c|}
\hline $\begin{array}{c}\text { Number of } \\
\text { neuron in } \\
\text { hidden layer }\end{array}$ & Epoch & $\mathrm{R}$ \\
\hline 3 & 55 & 0.25 \\
\hline 5 & 40 & 0.33 \\
\hline 9 & 81 & 0.45 \\
\hline 15 & 14 & 0.64 \\
\hline 20 & 22 & 0.78 \\
\hline 25 & 27 & 0.89 \\
\hline 30 & 12 & 1 \\
\hline
\end{tabular}

Figure 31 shows the prediction of a 3-minute alarm percentage. This prediction is done using the developed NARX model. It helps protect vehicle drivers from a problem that may occur during the trip. In addition, it provides the necessary information that assist in avoiding an event that may lead to interruption of traffic.

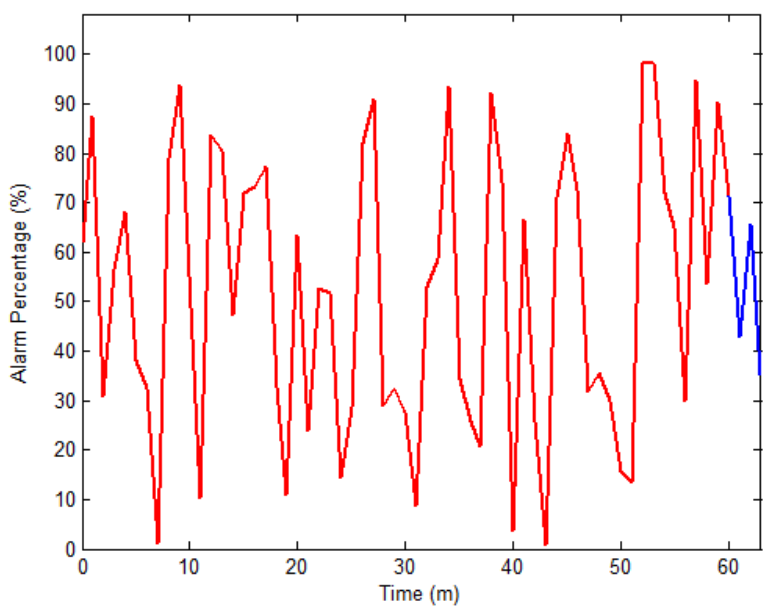

Fig. 31. Three minutes alarm percentage (\%) prediction.

\section{CONCLUSION}

In this paper, a multi agent system is developed to provide a robust vehicle to vehicle communication system in a noisy environment. The developed system has a decision mechanism which is based on NARX neural network. Vehicle Monitoring Agents and Central Monitoring Agent are implemented. The developed system was tested using real driver data collected during real trips. The system performs as designed. It succeeded in providing a predicted alarm percentage to the vehicle driver and correctly sending it to the surrounding vehicles.

\section{ACKNOWLEDGMENT}

The author wishes to express his thanks for the support of Tafila Technical University. Also, the author is very grateful for the support of Anwar Makka company for providing the vehicles parts used in the conducted experiments. 


\section{References}

[1] M. A. Masrur et al., "Military-Based Vehicle-to-Grid and Vehicle-to-Vehicle Microgrid-System Architecture and Implementation," in IEEE Transactions on Transportation Electrification, vol. 4, no. 1, pp. 157-171, March 2018.

[2] J. Thunberg, N. Lyamin, K. Sjöberg and A. Vinel, "Vehicle-to-Vehicle Communications for Platooning: Safety Analysis," in IEEE Networking Letters, vol. 1, no. 4, pp. 168-172, Dec. 2019.

[3] W. Shieh, C. J. Hsu, C. Lin and T. Wang, "Investigation of Vehicle Positioning by Infrared Signal-Direction Discrimination for Short-Range Vehicle-to-Vehicle Communications," in IEEE Transactions on Vehicular Technology, vol. 67, no. 12, pp. 11563-11574, Dec. 2018.

[4] K. Guan et al., "5-GHz Obstructed Vehicle-to-Vehicle Channel Characterization for Internet of Intelligent Vehicles," in IEEE Internet of Things Journal, vol. 6, no. 1, pp. 100-110, Feb. 2019.

[5] Y. S. Lam, J. J. Q. Yu, Y. Hou and V. O. K. Li, "Coordinated Autonomous Vehicle Parking for Vehicle-toGrid Services: Formulation and Distributed Algorithm," in IEEE Transactions on Smart Grid, vol. 9, no. 5, pp. 43564366, Sept. 2018.

[6] L. Zhang and G. Orosz, "Beyond-Line-of-Sight Identification by Using Vehicle-to-Vehicle Communication," in IEEE Transactions on Intelligent Transportation Systems, vol. 19, no. 6, pp. 1962-1972, June 2018.

[7] J. Pachat, N. S. Karat, P. P. Deepthi and B. S. Rajan, "Index Coding in Vehicle to Vehicle Communication," in IEEE Transactions on Vehicular Technology, vol. 69, no. 10, pp. 11926-11936, Oct. 2020.

[8] W. B. Qin and G. Orosz, "Experimental Validation of String Stability for Connected Vehicles Subject to Information Delay," in IEEE Transactions on Control Systems Technology, vol. 28, no. 4, pp. 1203-1217, July 2020.

[9] C. R. Storck and F. Duarte-Figueiredo, "A Survey of 5G Technology Evolution, Standards, and Infrastructure Associated With Vehicle-to-Everything Communications by Internet of Vehicles," in IEEE Access, vol. 8, pp. 117593-117614, 2020.

[10] H. Jiang, Z. Zhang, L. Wu and J. Dang, "A Non-Stationary Geometry-Based Scattering Vehicle-to-Vehicle MIMO Channel Model," in IEEE Communications Letters, vol. 22, no. 7, pp. 1510-1513, July 2018.

[11] H. Ko, S. Pack and V. C. M. Leung, "Mobility-Aware Vehicle-to-Grid Control Algorithm in Microgrids," in IEEE Transactions on Intelligent Transportation Systems, vol. 19, no. 7, pp. 2165-2174, July 2018.

[12]H. Jiang, Z. Zhang, L. Wu and J. Dang, "Novel 3-D Irregular-Shaped Geometry-Based Channel Modeling for Semi-Ellipsoid Vehicle-to-Vehicle Scattering Environments," in IEEE Wireless Communications Letters, vol. 7, no. 5, pp. 836-839, Oct. 2018.

[13]Z. Liu, Y. Xie, Y. Yuan, K. Ma, K. Y. Chan and X. Guan, "Robust Power Control for Clustering-Based Vehicle-toVehicle Communication," in IEEE Systems Journal, vol. 14, no. 2, pp. 2557-2568, June 2020.
[14]H. A. Ameen et al., "A Deep Review and Analysis of Data Exchange in Vehicle-to-Vehicle Communications Systems: Coherent Taxonomy, Challenges, Motivations, Recommendations, Substantial Analysis and Future Directions," in IEEE Access, vol. 7, pp. 158349-158378, 2019.

[15] T. Limbasiya and D. Das, "Lightweight Secure Message Broadcasting Protocol for Vehicle-to-Vehicle Communication," in IEEE Systems Journal, vol. 14, no. 1, pp. 520-529, March 2020.

[16] J. He, Z. Tang, Z. Fan and J. Zhang, "Enhanced Collision Avoidance for Distributed LTE Vehicle to Vehicle Broadcast Communications," in IEEE Communications Letters, vol. 22, no. 3, pp. 630-633, March 2018.

[17]Z. Ma, Q. Huo, X. Yang and X. Zhao, "Safety Cruise Control of Connected Vehicles Using Radar and Vehicleto-Vehicle Communication," in IEEE Systems Journal, vol. 14, no. 3, pp. 4602-4613, Sept. 2020.

[18] J. Zhou, Z. Chen, H. Jiang and H. Kikuchi, "Channel modelling for vehicle-to-vehicle MIMO communications in geometrical rectangular tunnel scenarios," in IET Communications, vol. 14, no. 19, pp. 3420-3427, 112 2020.

[19] X. Mou, D. T. Gladwin, R. Zhao, H. Sun and Z. Yang, "Coil Design for Wireless Vehicle-to-Vehicle Charging Systems," in IEEE Access, vol. 8, pp. 172723-172733, 2020.

[20] S. Hung, X. Zhang, A. Festag, K. Chen and G. Fettweis, "Vehicle-Centric Network Association in Heterogeneous Vehicle-to-Vehicle Networks," in IEEE Transactions on Vehicular Technology, vol. 68, no. 6, pp. 5981-5996, June 2019.

[21] H. Mei, J. Ding, J. Zheng, X. Chen and W. Liu, "Overview of Vehicle Optical Wireless Communications," in IEEE Access, vol. 8, pp. 173461-173480, 2020.

[22] B. Fan, H. Tian, S. Zhu, Y. Chen and X. Zhu, "TrafficAware Relay Vehicle Selection in Millimeter-Wave Vehicle-to-Vehicle Communication," in IEEE Wireless Communications Letters, vol. 8, no. 2, pp. 400-403, April 2019.

[23] L. Zhang, "Cooperative adaptive cruise control in mixed traffic with selective use of vehicle-to-vehicle communication," in IET Intelligent Transport Systems, vol. 12, no. 10, pp. 1243-1254, 122018.

[24] J. Lan and D. Zhao, "Min-Max Model Predictive Vehicle Platooning With Communication Delay," in IEEE Transactions on Vehicular Technology, vol. 69, no. 11, pp. 12570-12584, Nov. 2020.

[25] G. Fiengo, D. G. Lui, A. Petrillo, S. Santini and M. Tufo, "Distributed Robust PID Control For Leader Tracking in Uncertain Connected Ground Vehicles With V2V Communication Delay," in IEEE/ASME Transactions on Mechatronics, vol. 24, no. 3, pp. 1153-1165, June 2019.

[26]H. Nguyen et al., "Impact of Big Vehicle Shadowing on Vehicle-to-Vehicle Communications," in IEEE Transactions on Vehicular Technology, vol. 69, no. 7, pp. 6902-6915, July 2020.

[27] V. -L. Nguyen, P. -C. Lin and R. -H. Hwang, "Enhancing Misbehavior Detection in 5G Vehicle-to-Vehicle 
Communications," in IEEE Transactions on Vehicular Technology, vol. 69, no. 9, pp. 9417-9430, Sept. 2020.

[28]Z. Liu, X. Han, Y. Liu and Y. Wang, "D2D-Based Vehicular Communication With Delayed CSI Feedback," in IEEE Access, vol. 6, pp. 52857-52866, 2018.

[29] H. Jiang, Z. Zhang, L. Wu, J. Dang and G. Gui, "A 3-D Non-Stationary Wideband Geometry-Based Channel Model for MIMO Vehicle-to-Vehicle Communications in Tunnel Environments," in IEEE Transactions on Vehicular Technology, vol. 68, no. 7, pp. 6257-6271, July 2019.

[30] Rashdan, F. de Ponte Müller, S. Sand, T. Jost and G. Caire, "Measurement-based geometrical characterisation of the vehicle-to-vulnerable-road-user communication channel," in IET Microwaves, Antennas \& Propagation, vol. 14, no. 14, pp. 1700-1710, 25112020.

[31]M. Yang et al., "A Cluster-Based Three-Dimensional Channel Model for Vehicle-to-Vehicle Communications," in IEEE Transactions on Vehicular Technology, vol. 68, no. 6, pp. 5208-5220, June 2019.

[32] S. Gill, B. Aygun, K. N. Heath, R. J. Gegear, E. F. Ryder and A. M. Wyglinski, "Memory Matters: Bumblebee Behavioral Models for Vehicle-to-Vehicle Communications," in IEEE Access, vol. 6, pp. 2543725447, 2018.

[33] Alturiman and M. Alsabaan, "Impact of Two-Way Communication of Traffic Light Signal-to-Vehicle on the Electric Vehicle State of Charge," in IEEE Access, vol. 7, pp. 8570-8581, 2019.

[34] H. Jiang, W. Ying, J. Zhou and G. Shao, "A 3D Wideband Two-Cluster Channel Model for Massive MIMO Vehicleto-Vehicle Communications in Semi-Ellipsoid Environments," in IEEE Access, vol. 8, pp. 23594-23600, 2020.

[35] V. Hassija, V. Chamola, G. Han, J. J. P. C. Rodrigues and M. Guizani, "DAGIoV: A Framework for Vehicle to Vehicle Communication Using Directed Acyclic Graph and Game Theory," in IEEE Transactions on Vehicular Technology, vol. 69, no. 4, pp. 4182-4191, April 2020.

[36] B. Zhou et al., "Optimal Coordination of Electric Vehicles for Virtual Power Plants With Dynamic Communication Spectrum Allocation," in IEEE Transactions on Industrial Informatics, vol. 17, no. 1, pp. 450-462, Jan. 2021.

[37]M. Sepulcre and J. Gozalvez, "Heterogeneous V2V Communications in Multi-Link and Multi-RAT Vehicular Networks," in IEEE Transactions on Mobile Computing, vol. 20, no. 1, pp. 162-173, 1 Jan. 2021.

[38] W. Li, Z. Xie, P. K. Wong, X. Mei and J. Zhao, "AdaptiveEvent-Trigger-Based Fuzzy Nonlinear Lateral Dynamic Control for Autonomous Electric Vehicles Under Insecure Communication Networks," in IEEE Transactions on Industrial Electronics, vol. 68, no. 3, pp. 2447-2459, March 2021.

[39] Ayman M. Mansour, "GSM based Vehicle-to-Vehicle Communication using Multi-Agent Intelligent System," WSEAS Transactions on Electronics, Vol. 10, 2019.

[40] Ayman M. Mansour, "Intelligent E-Health System for Patient and Elderly People Monitoring Using Multi Agents System," Jordan Journal of Electrical Engineering, Vol. 4, no. $1,2018$.
[41]Bilal Hawashin, and Ayman Mansour, "An Efficient Agent-Based System to Extract Interests of User Groups," Lecture Notes in Engineering and Computer Science: Proceedings of The World Congress on Engineering and Computer Science, vol. 1, pp. 444-448, October 2016.

[42] Ayman Mansour, Hao Ying, Peter Dews, Yanqing Ji, and R. Michael Massanari, "Identifying Adverse Drug Reaction Signal Pairs by a Multi-Agent Intelligent System with Fuzzy Decision Model," Proceedings of the 31st North American Fuzzy Information Processing Society Conference, Berkeley, CA, August 6-8, 2012.

[43] Ayman Mansour, Hao Ying, Peter Dews, Yanqing Ji, Margo Farber, John Yen, Richard E. Miller, and R. Michael Massanari, "A Multi-Agent System for Detecting Adverse Drug Reactions," Proceedings of the 29th North American Fuzzy Information Processing Society Conference, Toronto, ON, Canada, July 12-14, 2010.

[44] Mohammad A Obeidat, L.Y. Wang, F. Lin, "Real-Time Parameter Estimation of PMDC Motors using Quantized Sensors," IEEE Transactions on Vehicular Technology, Vol. 62, no. 6, pp. 1- 10, July 2013.

[45] Mohammad A Obeidat, L.Y. Wang, F. Lin, Online Parameter Estimation of PMDC Motors using Quantized Output Observations, ITEC IEEE Transportation Electrification Conference, Dearborn, Dearborn, Michigan, June 18-20, 2012.

[46] Mohammad A Obeidat, L.Y. Wang, F. Lin, "On-Line Parameter Estimation of PMDC Motors using BinaryValued Speed Measurements, PECI Power and Energy Conference at Illinois, University of Illinois at Urbana Champaign, Illinois, February 24-25, 2012.

[47] Mohammad A Obeidat, "Real-Time DC Servomotor Identification and Control of Mechanical Braking System for Vehicle-to-Vehicle Communication," International Journal of Computer Applications, Vol. 182, no. 40, PP. 20-30, February 2019.

[48]Zeinab El-Rewini, Karthikeyan Sadatsharan, Daisy Flora Selvaraj, Siby Jose Plathottam, Prakash Ranganathan,"Cybersecurity challenges in vehicular communications," Vehicular Communications, Vol. 23, 2020,

[49] Jing Xie \& Chen-Ching Liu ,"Multi-agent systems and their applications," Journal of International Council on Electrical Engineering, Vol. 7, no. 1, pp. 188-197,2017.

[50] Ruiz LG'B, Cuéllar MP, Calvo-Flores MD, Jiménez MDCP. "An Application of Non-Linear Autoregressive Neural Networks to Predict Energy Consumption in Public Buildings," Energies, Vol. 9, no. 9, 2016.

[51] Xie H., Tang H. and Liao Y. H, "Time Series Prediction Based on NARX Neural Networks: An Advanced Approach," Paper presented at the 2009 International Conference on Machine Learning and Cybernetics, Baoding, China, 12-15 July 2009.

[52] Abdulkadir SJ, Yong S-P, "Scaled UKF-NARX hybrid model for multi-step-ahead forecasting of chaotic time series data," Soft Comput, Vol. 19, pp. 3479-3496, 2015. 
[53] Linda Kanaan, Jamal Haydar, Mounir Samaha, Ali Mokdad, Walid Fahs, "Intelligent Bus Application for Smart City based on LoRa Technology and RBF Neural Network," WSEAS Transactions on Systems and Control, pp. 725-732, Vol. 15, 2020.

[54] J. R. Landis and G. G. Koch, "The measurement of observer agreement for categorical data," Biometrics, vol. 33, p. 159, 1977.

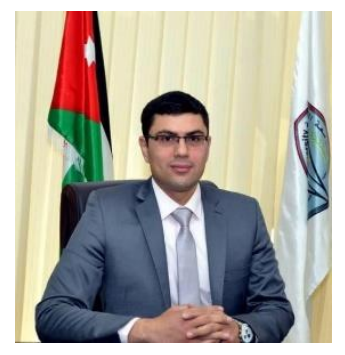

Dr. Ayman M Mansour received his Ph.D. degree in Electrical Engineering from Wayne State University in 2012. Dr. Mansour received his M.Sc degree in Electrical Engineering from University of Jordan, Jordan, in 2006 and his B.Sc degree in Electrical and Electronics Engineering from University of Sharjah, UAE, in 2004. He graduated top of his class in both Bachelor and Master. Currently, Dr. Mansour is an Associate Professor in the Department of Communication, Electronics and Computer Engineering, Tafila Technical University, Jordan. He is also the director of the Quality Assurance Center at Tafila Technical University. His areas of research include Communication Systems, Multi-agent Systems, Fuzzy Systems, Renewable Energy, Data Mining and Intelligent Systems. He conducted several researches in his area of interest. Dr. Mansour is a member of IEEE, Michigan Society of Professional Engineers, IEEE Honor Society (HKN), Society of Automotive Engineers (SAE), Tau Beta Pi Honor Society, Sigma Xi and Golden Key Honor Society.

\section{Creative Commons Attribution License 4.0 (Attribution 4.0 International, CC BY 4.0)}

This article is published under the terms of the Creative Commons Attribution License 4.0 https://creativecommons.org/licenses/by/4.0/deed.en US 